\title{
Automatic gate design model from wood \& tire for farmers
}

\author{
Ivan Indrawan ${ }^{1}$, Nursyamsi ${ }^{1}$, Sayed Iskandar Muda $^{1}$ \\ ${ }^{1}$ Department of Civil Engineering, Engineering Faculty, University of Sumatera Utara, 20155 Medan, Indonesia
}

\begin{abstract}
Indonesia is one of the potential paddy farming area in Southeast Asia, and North Sumatra Province is one of many provinces that provides it. Yet, Indonesia is still importing rice from foreign country, eventhough today the government has been willing to supply its own need. Almost $10 \%$ irrigation areas in Indonesia are connected to sea current, which means it must have a system to manage the circulation of fresh water and block the seawater from entering the irrigation area through the irrigation channel. Many systems use gates to control the water management, and most of them are using automatic sluice gate because the gates are usually positioned far from village, this makes the manual operating become difficult. Unfortunately, not all farmers can use this kind of gate due to its accessibility and cost. This research was done to design the automatic gates, which are easy to build, user friendly, low cost and dependable. In the future, poor farmers or farmers who do not have connection to government, can make this gate by themselves. The research was conducted in laboratory, using flume, pumps, reservoir, and gate prototype.
\end{abstract}

\section{Introduction}

Over 9.136.028 hectares (Permen PUPR No.14, 2015) of paddy field in Indonesia, some of them did not have a technical irrigation [1]. The irrigation infrastructure should keep the paddy production sustainable. When the production went down, most of the farmers gave up and turned into other crops such as palm which requires less water and infrastructure. This condition would be the opposite of the willing of government to become selfsufficient rice country. One of many problems that the farmers have to deal with is the irrigation gate. This gate should be an instrument which holds the water during ponding stage and drains the water when its flooding stage. The gate must be built by private company or with help from the government which is so difficult to process. This paper will answer the challenge to create a gate that is affordable, easy to install and operate, without ignoring the basic principles of fluid mechanics and hydraulics theory. The gates are made from wood and rubber tire (bicycle tire), and formulated from Buoyancy and Flotation theory.

This paper will give the result of the gate experiment which shows the design of gates, specification of gates, and installation-operational manual. The basic principle of buoyancy and flotation was first discovered and stated by Archimedes which states that a body which is floating or submerging in a fluid is buoyed (lifted) upward by force equals to the weight of the body that would be displaced by fluid. The force is known as buoyant force. It shows that the floating body displaces sufficient volume of fluid to balance its own weight. The point which the buoyant force act occurred is called the centre buoyancy, it is located at the centre of gravity of the displaced fluid $[4,7]$.

If the weight of an object is less than the displaced fluid, the object rises, as in the case of a block of wood that is released beneath the surface of water or a helium-filled balloon that is let loose in air. An object heavier than the amount of the fluid it displaces, will sink when released, it has an apparent weight loss equal to the weight of the fluid displaced. In fact, in some accurate weighings, a correction must be made in order to compensate the buoyancy effect of the surrounding air. The buoyant force, which always opposes gravity, is nevertheless caused by gravity [10]. Fluid pressure increases with depth because of the (gravitational) weight of the fluid above. This increasing pressure applies a force on a submerged object that increases within depth. The result is buoyancy [3].

\section{Experiment details}

\subsection{Automatic gate model}

The dimension of the gate is $40 \mathrm{~cm} \mathrm{x} 40 \mathrm{~cm}$ x $15 \mathrm{~cm}$, made from first class of wood (Damar Laut), 1 inch thickness

\footnotetext{
Corresponding author: ivanindrawan76@gmail.com
} 
[2]. The gate designed as a pocket filled with rocks to have significant weight. The gate was coated with oil-paint. The upstream side of the gate has been installed with a rubber bicycle tube tire (Fig.1). All the materials of the gate was meant to be simple and available everywhere, such as plank wood used from ex-building material as long as it meets the gate's dimension and the bicycle tire, which we assume most of the farmer in Indonesia have it. The bicycle tire attached to wooden gate is made to give buoyancy to the gate at significant water level. The wood and rubber tire will manage the water circulation from upstream to downstream automatically. The main principle is to keep the gate closed at $\mathrm{W}$ weight and opened at water level, $y$, by adding air to the tire rubber as pressure to the gate, FU, until the gate opened at a significant water level. The schematic of instrument shown as figure 4 .

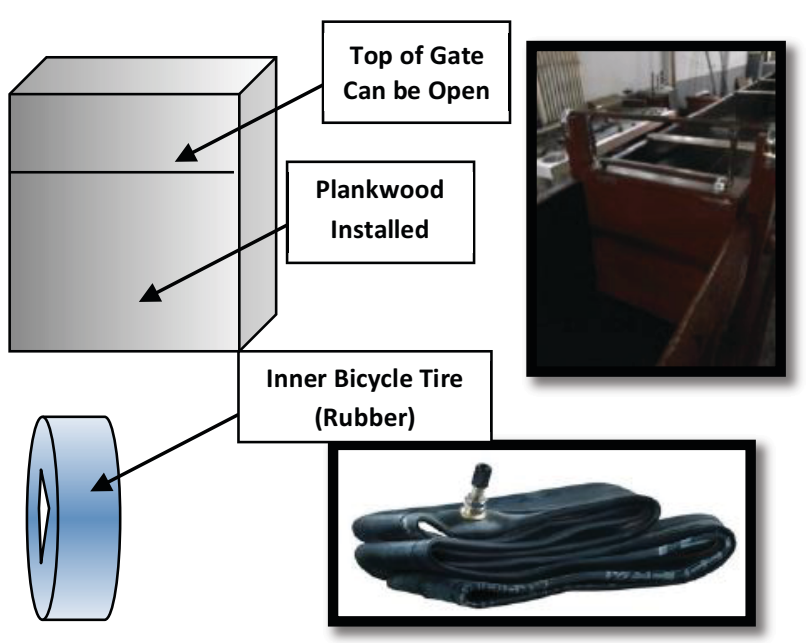

Fig. 1. Material of gate

\subsection{Experiment procedures}

The experiment measures the height of water at upstream (hu), at the gate (hp) and at downstream (hi). The measurement is conducted at different flow velocity from $0.4 \mathrm{~m} / \mathrm{s}$ to $0.1 \mathrm{~m} / \mathrm{s}$, with a constant weight of wooden gate, where the pressure at rubber tire set from zero to maximum. This figure below explains where the point of measurement is taken.

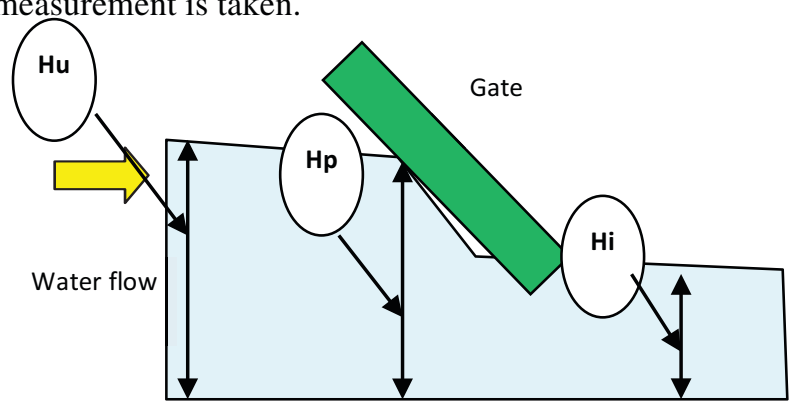

Fig.2. Point of measurement
Procedure of experiment conducted as follow:

1. The top of the gate open and filled with rock to make significant weight so the gate remain closed until the purposed water level is achieved. Make sure the tire tube is attached to gate.

2. The water flows into the flume. The gate must be filled again with rock to add the weight in order to make the gate remain closed.

3. When the gate is opened, it is expected that the water level on downstream is lower than 1/10 height of gate. Otherwise, the weight of the gate should be added. Then, the tire will manage the gate for purposed height of water on downstream.

4. The air volume inside the tube tire (inner tube) gives bouyant force to lift the gate. The adding of air volume uses air hand pump which formerly used for bicycle tire. The height water at downstream can be adjusted by adding the volume of air.

5. To close the gate when needed, the airinside the tire tube can be released by simply opening the tire tube valve. All the methodology of the experiment are repeated and recorded in experiment's form for analysis.

This figure below shows how the experiment was conducted.

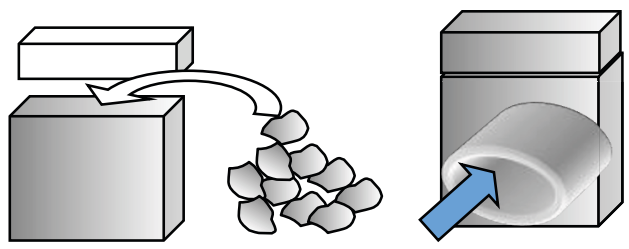

(1)

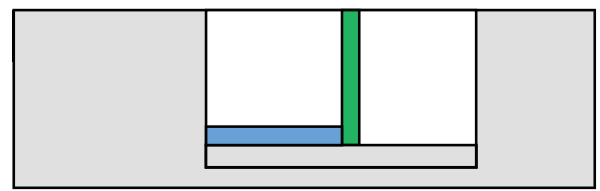

(2)

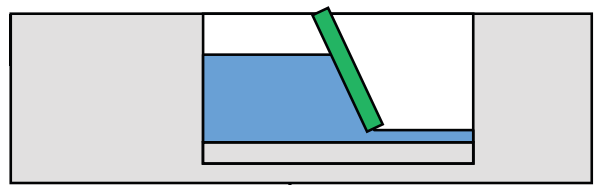

(3)

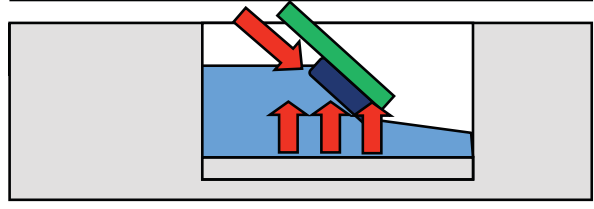

(4)

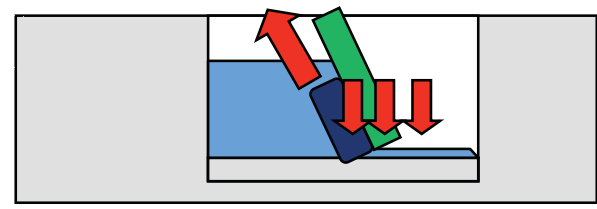

Fig. 3. Experiment procedure 


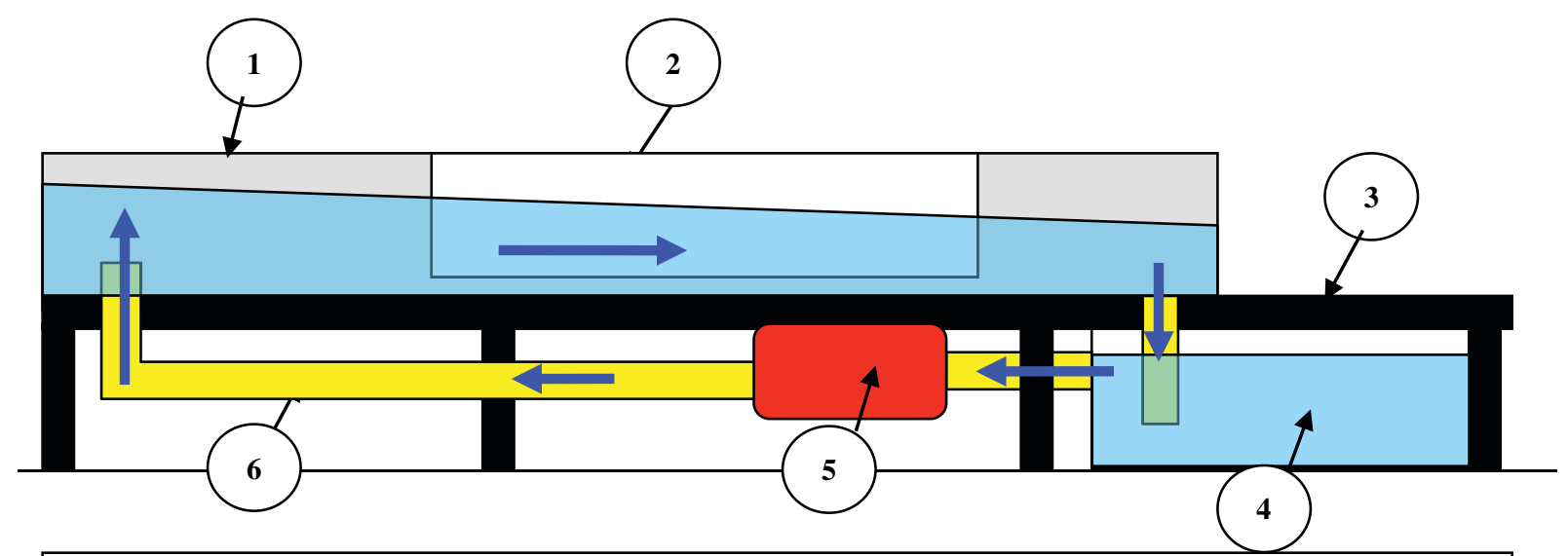

Annex:

1. Flume, for water flow, made from plywood $9 \mathrm{~mm}$, size $40 \mathrm{~cm} \mathrm{x} 40 \mathrm{~cm} \mathrm{x} 1500 \mathrm{~cm}$

2. Glass, for observation view

3. Steel framework, for flume supporting and leveling.

4. Reservoir, for water circulating

5. Pump, for pumping and sucting water, with 10 litre per-second capacity

6. Pipe, for water flow, PVC 2" diameter

Fig. 4.(a) Instrumentation of experiment
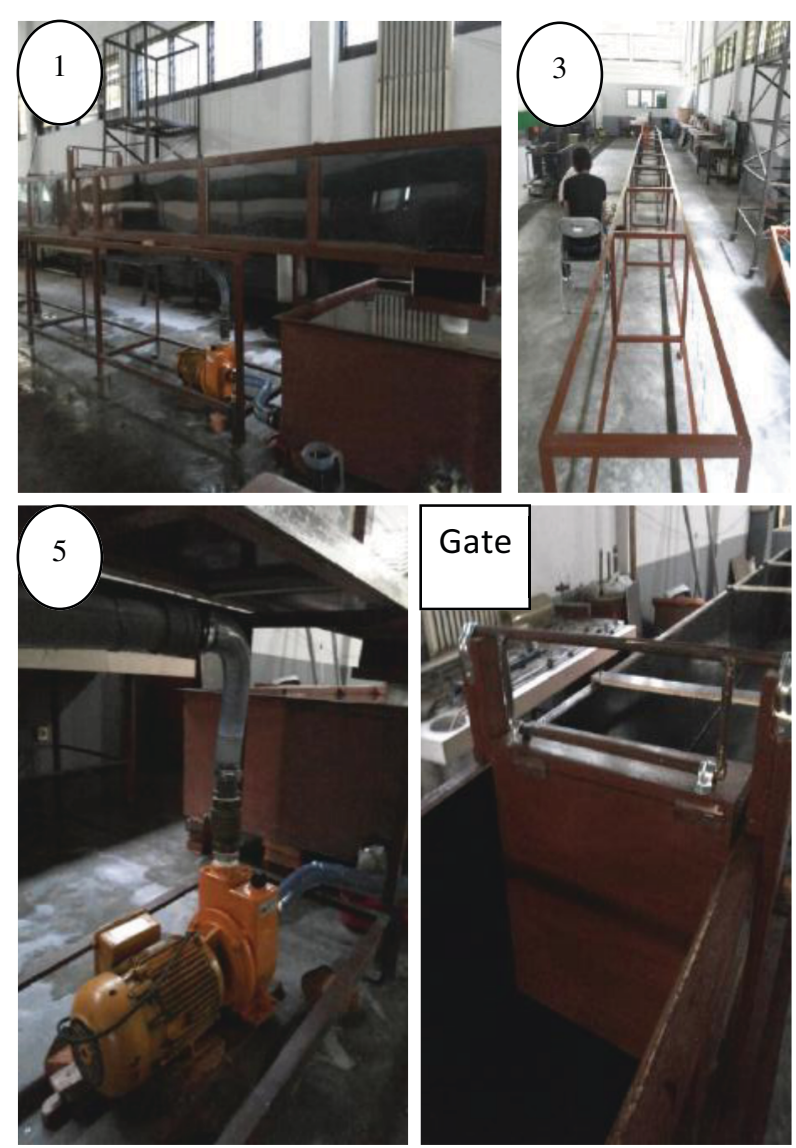

Fig. 4.(b) Instrumentation of experiment

\section{Result and discussion}

After trial and error procedure to set up the constant weight by filling the gate with rock gradually, the optimum result for the weight is $41 \mathrm{~kg}$. This trial and error procedure was done at maximum velocity and zero pressure. After the weight of gate is set, then the experiment was carried on with the following procedure above. The result of experiment is shown in table below.

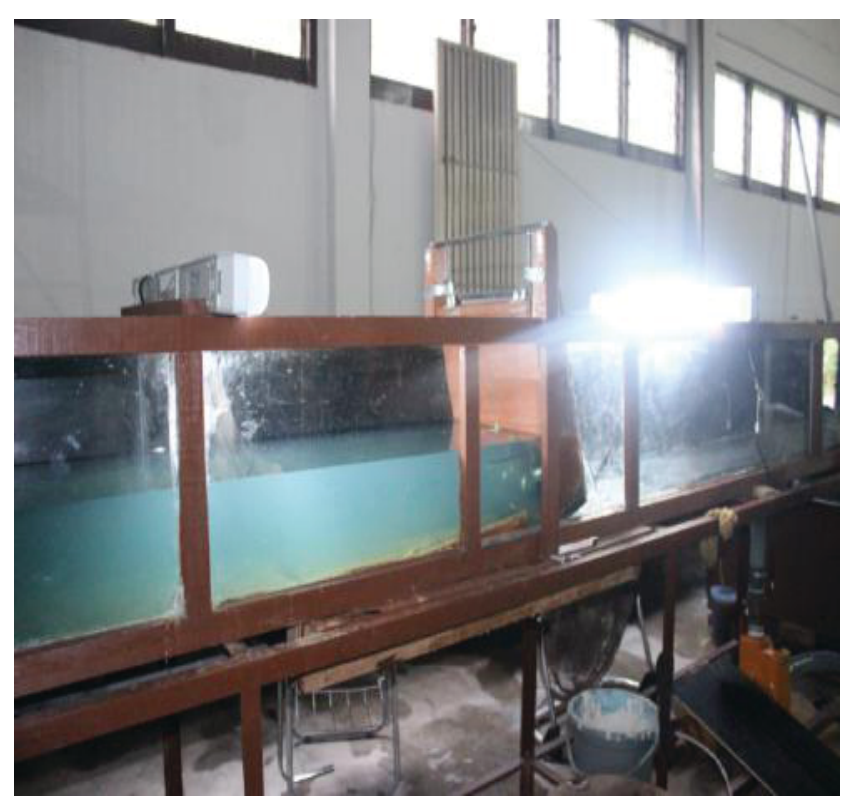

Fig. 5. Condition of gate at pressure $=0$ 
Table 1. Result at pressure $=$ maximum

\begin{tabular}{|c|l|c|c|c|c|}
\hline No. & $\begin{array}{l}\text { Velocity } \\
(\mathbf{m} / \mathbf{s})\end{array}$ & $\begin{array}{c}\text { Hu } \\
(\mathbf{m m})\end{array}$ & $\begin{array}{c}\text { Hp } \\
(\mathbf{m m})\end{array}$ & $\begin{array}{c}\text { Hi } \\
(\mathbf{m m})\end{array}$ & $\begin{array}{c}\text { Opened Gate } \\
(\mathbf{m m})\end{array}$ \\
\hline 1 & 0.40 & 281 & 281 & 21 & 241 \\
\hline 2 & 0.35 & 279 & 279 & 19.5 & 238 \\
\hline 3 & 0.30 & 276 & 276 & 17.5 & 235 \\
\hline 4 & 0.25 & 272 & 272 & 16 & 232.5 \\
\hline 5 & 0.20 & 269 & 269 & 15 & 229 \\
\hline 6 & 0.15 & 266 & 266 & 14 & 217 \\
\hline 7 & 0.10 & 263 & 263 & 12.5 & 214 \\
\hline 8 & 0.05 & 262.0 & 262.0 & 0.0 & 0.0 \\
\hline 9 & 0.03 & 261.0 & 261.0 & 0.0 & 0.0 \\
\hline
\end{tabular}

Table 2. Result at pressure $=0$

\begin{tabular}{|c|c|c|c|c|c|}
\hline No. & $\begin{array}{c}\text { Velocity } \\
(\mathbf{m} / \mathbf{s})\end{array}$ & $\begin{array}{c}\text { Hu } \\
(\mathbf{m m})\end{array}$ & $\begin{array}{c}\text { Hp } \\
(\mathbf{m m})\end{array}$ & $\begin{array}{c}\text { Hi } \\
(\mathbf{m m})\end{array}$ & $\begin{array}{c}\text { Opened Gate } \\
(\mathbf{m m})\end{array}$ \\
\hline 1 & 0.40 & 270.0 & 270.0 & 33.0 & 235 \\
\hline 2 & 0.35 & 267.0 & 267.0 & 31.5 & 229 \\
\hline 3 & 0.30 & 263.5 & 263.5 & 29.5 & 225 \\
\hline 4 & 0.25 & 260.0 & 260.0 & 27.5 & 222 \\
\hline 5 & 0.20 & 257.0 & 257.0 & 26.0 & 216 \\
\hline 6 & 0.15 & 255.0 & 255.0 & 24.5 & 213 \\
\hline 7 & 0.10 & 253.0 & 253.0 & 23.0 & 208 \\
\hline 8 & 0.05 & 252.0 & 252.0 & 0.0 & 0.0 \\
\hline 9 & 0.03 & 251.0 & 251.0 & 0.0 & 0.0 \\
\hline
\end{tabular}

From the experiment, it is shown that the weight required to make the gate remain closed is $41 \mathrm{~kg}$. At zero pressure in tire tube, to start opening the gate, requires $253 \mathrm{~mm}$ height of the water at upstream point. Meanwhile, the gate is opened about $23 \mathrm{~mm}$ height of water at downstream point. At maximum pressure in tire tube, to start opening the gate, requires $263 \mathrm{~mm}$ height of the water at upstream point. Meanwhile, the gate is opened about $12.5 \mathrm{~mm}$ height of water at downstream point.

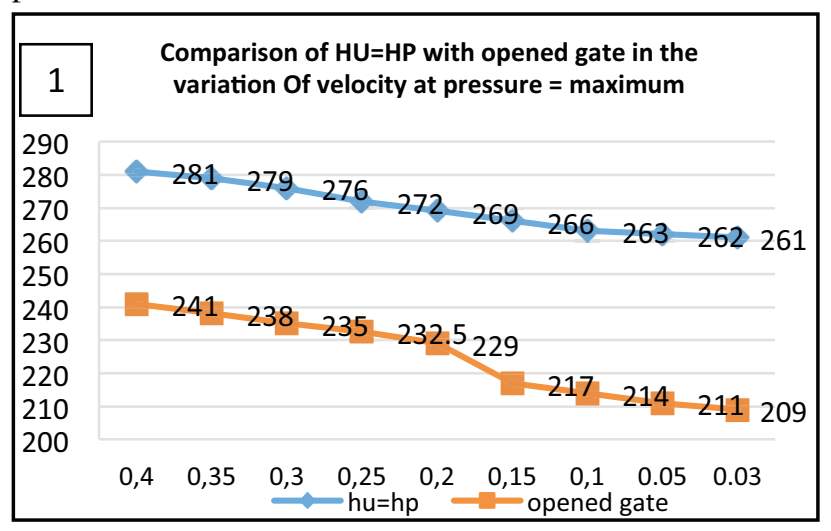

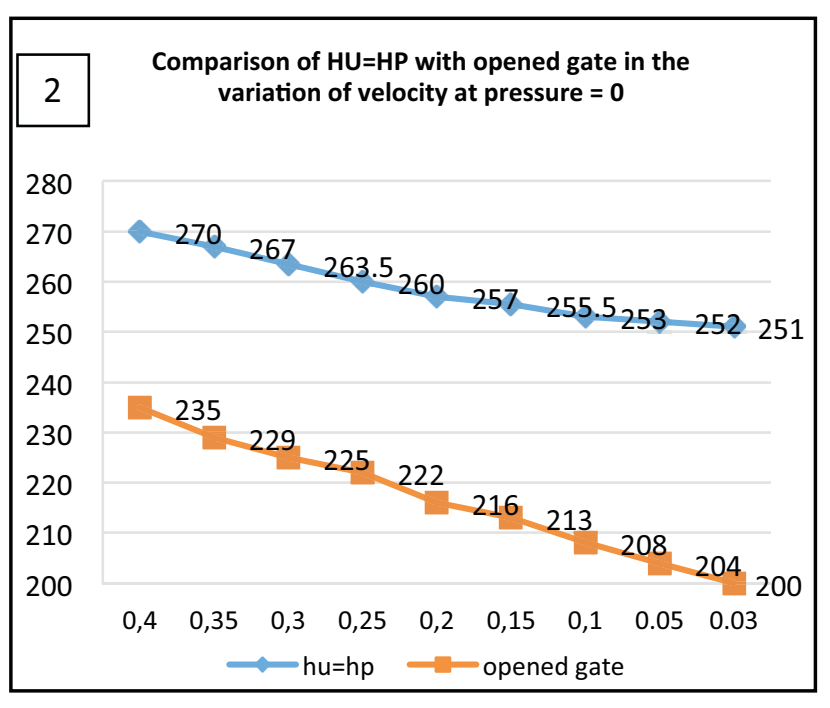

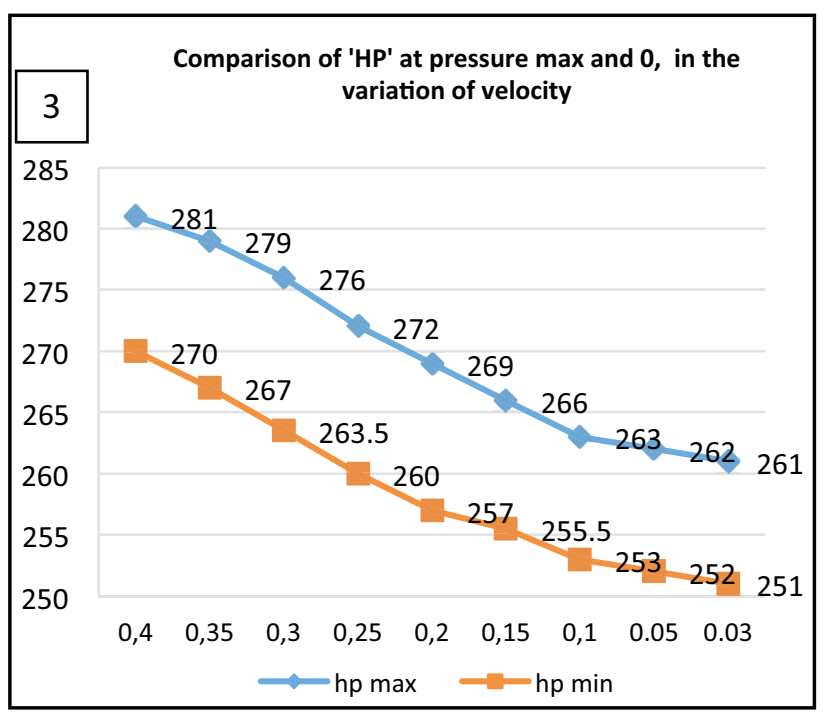

Comparison of 'HI' at pressure max and 0 , in the variation of velocity

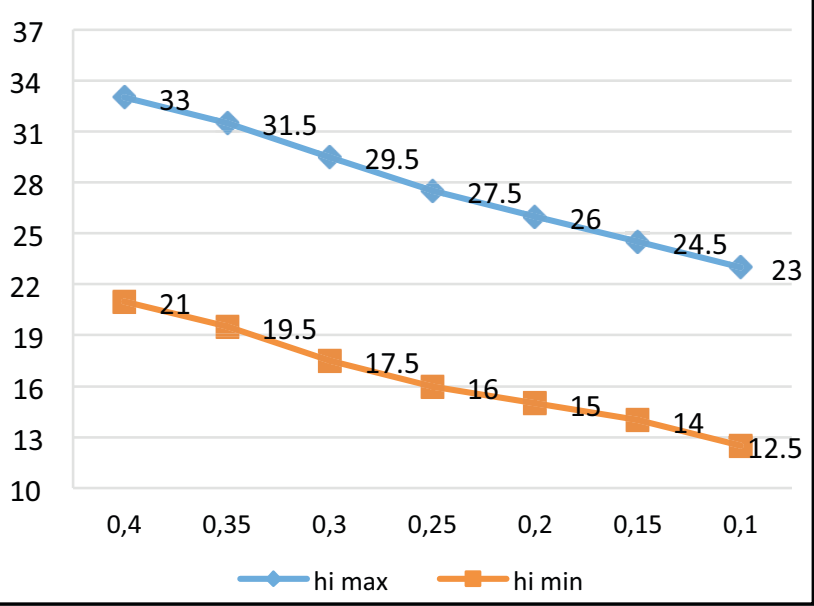


Fig. 6. Relationship between various water level, pressure and velocity

\section{Experiment result - analysis}

This chapter is explaining the math to analyse behaviour of the gate as it is sub-merged [5,9].

Assuming the wooden gate is a plane of area as figure bellow;

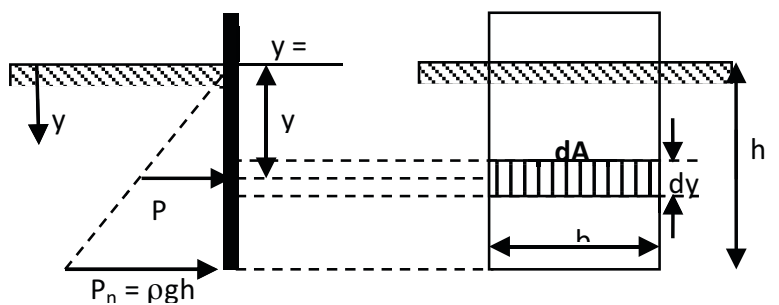

Fig. 7 Forced on a submerged plate

Force on plate work on element dA, where,

$$
d F=p . d A
$$

Since,

$$
p=\rho \cdot g \cdot y
$$

So,

$$
d F=\rho \cdot g \cdot y \cdot d A
$$

Then, total force on plate can be define as

$$
F_{R}=\int d F
$$

Which mean,

$$
F_{R}=\int \rho \cdot g \cdot y \cdot d A
$$

It is same as,

$$
F_{R}=\rho \cdot g \int y \cdot d A
$$

Where the equation fullfill the boundary of 0 to h. So the equation is,

$$
F_{R}=\rho \cdot g \int_{o}^{h} y \cdot d A
$$

Since, $A$ is area of $b$ and $y$, so integral of $y . d A$ result is

So,

$$
\int_{o}^{h} y \cdot d b \cdot y=b \cdot\left[\frac{1}{2} y^{2}\right]_{0}^{h}=1 / 2 b \cdot h^{2}
$$

$$
F_{R}=\rho \cdot g \cdot 1 / 2 \cdot b \cdot h^{2}=1 / 2 \cdot r \cdot g \cdot b \cdot h^{2}
$$

Besides the pressure from water flow, the force acting on gate is the weight of gate itself and the floating force from rubber tire [6], that is,

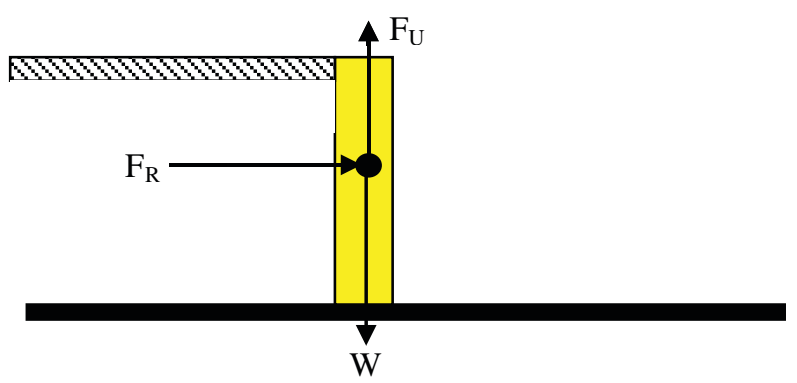

Fig. 8. Forced on a submerged plate

To make the gate remain close, we need balance equation, which is,

$$
F_{R}-W+F_{U}=0
$$

So,

$$
\mathrm{F}_{\mathrm{R}}=\mathrm{W}-\mathrm{F}_{\mathrm{U}}
$$

During the experiment, we use zero floating force in order to have a weight of the door at closed.

$$
\mathrm{F}_{\mathrm{R}}=\mathrm{W}-\mathrm{F}_{\mathrm{U}}
$$

Then, we add floating force using the rubber tire to make the gate opened.

$$
\mathrm{F}_{\mathrm{R}}-\mathrm{W}+\mathrm{F}_{\mathrm{U}}>0
$$

During the experiment the water flow start to push the gate to open until it reach its maximum height, $H p=$ maximum. The problem is when the water level is at low point, $0<\mathrm{Hp}<2 / 3 \mathrm{Hp}$ the gate is still open. Eventhough, this event can be applied as water flow management at the field, it should reach the optimumwater level point, $y$, before the gate open. In order to find the optimum point, we must calculate the centre of pressure.

Refering from figure 7 the equilibrium point can be described as figure below,

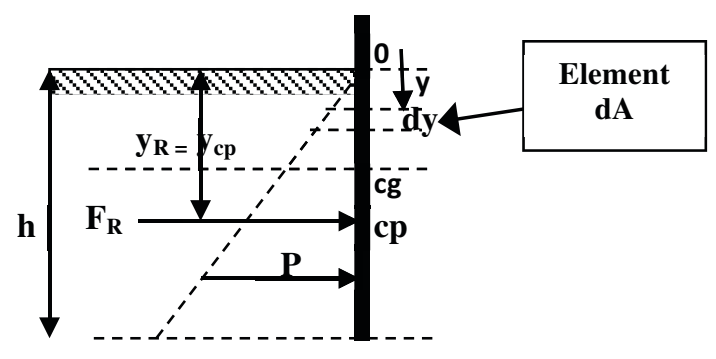

Fig. 9 Equilibrium point

For a plate in equilibrium we can take moments about any point, such as "0". Sum of moments on all elements $=$ moment of resultant force.

So,

$$
\begin{aligned}
& \int_{0}^{h} \rho \cdot g \cdot y \cdot d A \cdot y \\
= & \rho \cdot g \int_{0}^{h} y^{2} \cdot d A \\
= & \rho \cdot g \int_{0}^{h} y^{2} \cdot d(b \cdot y)
\end{aligned}
$$




$$
=\rho \cdot g \int_{0}^{h} b y^{2} d y
$$

$\int_{0}^{h} b y^{2} d y$, called as "second moment of area"

Then,

$$
\begin{gathered}
\rho g\left[1 / 3 b y^{3}\right]_{0}^{h} \\
=1 / 3 \rho g b h^{3}
\end{gathered}
$$

Since, $\int_{0}^{h} \rho \cdot g \cdot y \cdot d A \cdot y=\mathrm{F}_{\mathrm{R}} \cdot \mathrm{y}_{\mathrm{cp}}$ to reach equilibrium

Then,

$$
1 / 3 \rho g b h^{3}=\frac{\rho g h}{2} \cdot(b h) \cdot y_{c p}
$$

So the result is,

$$
\mathrm{y}_{\mathrm{cp}}=2 / 3 \mathrm{~h}
$$

Using $h$ as $h p$ in experiment, the result is that the gate is remain closed at $W, y, F_{U}$ at $0<\mathrm{Hp}<2 / 3 \mathrm{Hp}$. And then the gate start to open at $\mathrm{Hp}>2 / 3 \mathrm{Hp}$. This value will give an automatic control for farmer, so they don't have to control the gate as day to day activity. When the farmer needs $y_{l}$ (where $y_{l}>y_{c p}$ ) water level, $F_{U}$ should be increased by pumping air intotire tube. When the farmer need $y_{2}$ (where $y_{2}<y_{c p}$ ) water level, $F_{U}$ should be decreased through tire tube. Moreover, when the farmer keeps the water by closing the gate, the farmer should simply release air from tire tube. In Table 3 the point of experiment are described.

Table 3. Experimental Result Analysis

\begin{tabular}{|c|c|c|}
\hline $\begin{array}{c}\text { Water level } \\
\text { Condition at } 0- \\
30 \mathrm{~cm} \text { height } \\
(\mathrm{cm})\end{array}$ & $\begin{array}{c}\text { Gate Level } \\
\text { Condition at 25 } \\
\mathrm{kg} \text { weight }(\mathrm{cm})\end{array}$ & $\begin{array}{c}\text { Rubber Tire } \\
\text { Condition (psi) }\end{array}$ \\
\hline 0 & Close & $\mathrm{Fu}=0$ \\
\hline $0<\mathrm{hp}<15,4$ & Open, hi $=1,7$ & $\mathrm{Fu}=0$ \\
\hline $15,4<\mathrm{hp}<18,5$ & Open, hi $=3,1$ & $\mathrm{Fu}=0$ \\
\hline $18,5<\mathrm{hp}<20,0$ & Open, hi $=3,2$ & $\mathrm{Fu}=$ Maximum \\
\hline
\end{tabular}

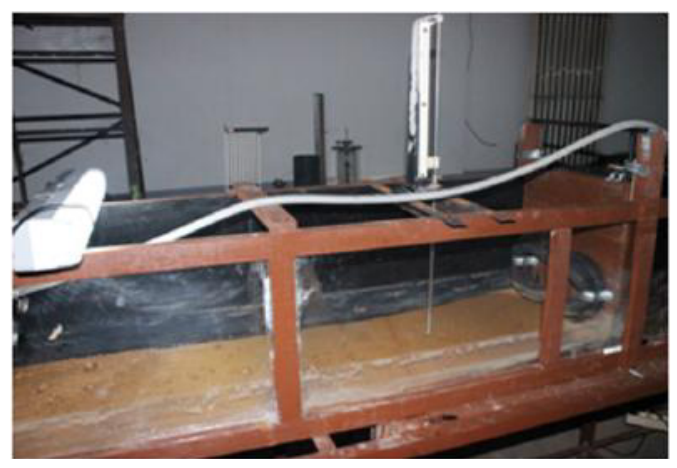

Fig. 10.a. The gate closed at water level 0

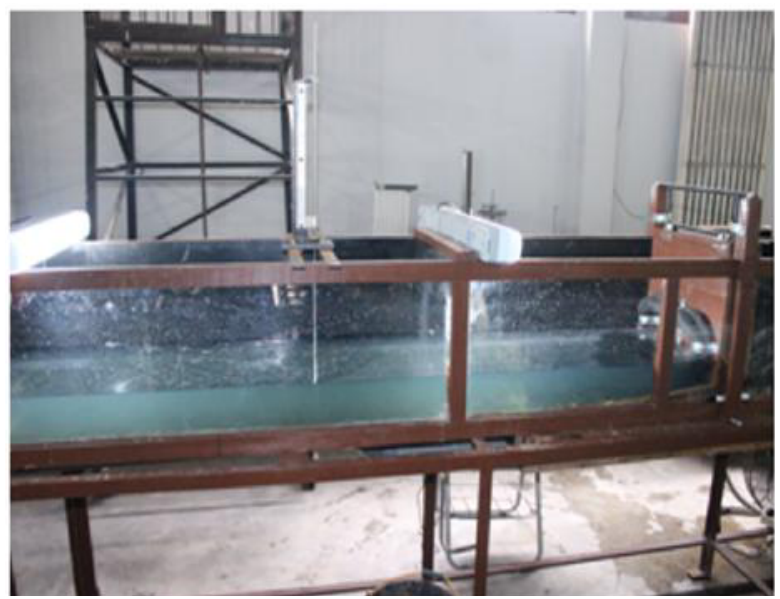

Fig. 10.b. The gate start to open at water level $h p<2 / 3 y$

Whether the result is not fullfiled in condition at equilibrium, as optimum level, this experiment can be used for farmer asa starting effort and for further research. Every possible options can be excecuted using the same model until we can build the prototype to be used by the farmers all of around Indonesia.

\section{Conclusion and recomendation}

Conclussion from this experiment is;

1. The gate with $41 \mathrm{~kg}$ weight was opened below at proposed point at $2 / 3 \mathrm{H}$ (since $\mathrm{H}=400 \mathrm{~mm}$, so $2 / 3 \mathrm{H}$ is $266 \mathrm{~mm}$ ). Its $281 \mathrm{~mm}$ the gate was open or it is $67 \%$ water level height require. So, the gate succeed toopened below at proposed point at $2 / 3 \mathrm{H}$.

2. Using Buoyancy and Floting Method, as described at experiment result analysis, the gate should be close at $W, y, F_{U}$ at $0<\mathrm{Hp}<2 / 3 \mathrm{Hp}$. And then the gate start to open at $\mathrm{Hp}>2 / 3 \mathrm{Hp}$. This value will give an automatic control for farmer, so they do not have to control the gate as day to day activity. When the farmer needs $y_{1}$ water level, $F_{U}$ should be increased by pumping air into the tire tube. When the farmer needs $y_{2}$ water level, $F_{U}$ should be decreased throughtire tube. And when the farmer keeps the water by closing the gate, the farmer should simply release air from tire tube.

Recomendation for completing the experiment;

1. The gate filler material must be changed so the weight required is fullfilled. Otherwise, the gate will function only in certain condition. And we are expecting the gates to be functional in all conditions

2. Sedimentation is necessary to be tested in this model 
3. since this problem eventually emerged in the field

4. Various velocity category must be tested to make the gates more useable.

\section{References}

1. Regulation of the Minister of Public Works and Public Housing Republic of Indonesia No. 14/2015 (2015)

2. Department of Public Works Republic of Indonesia, Regulation of Wood Constructions NI-5, PKKI1961, (1961), SNI 7973-2013 (2013)

3. Reed, B. Cameron. Physics education 39.4 (2004)

4. Ranald, V.Giles, Fluid Mechanics and Hydraulics, Schaum Outlines, McGraw-Hill (1995)
5. Triatmodjo, Bambang, Hidrolika I, Beta Offset, Yogyakarta (2001)

6. Kojima, Haruyuki, Takeshi Ijima, and Akinori Yoshida. Coastal Engineering 1990. 1228-1241. (1991).

7. Chen, Wai-Fah, and Lian Duan. Bridge Engineering Handbook: Superstructure Design. CRC press, 2014.

8. Eades, Andrew, and Jeffrey Penno.. U.S. Patent No. 7,037,432. 2 May (2006)

9. Groves, Michael F. U.S. Patent No. 5,716,041. 10 Feb. (1998)

10. Rempel, A. W., J. S. Wettlaufer, and M. G. Worster. Physical review letters 87.8 (2001) 